\title{
An Evaluation of the Lipiodol Test for the Detection of Steatorrhoea
}

\author{
JANET L. P. HUNTER, J. M. JOHNSTONE, and J. H. KEMP \\ From the Grimsby General Hospital, Grimsby, Lincs.
}

Since the introduction of Lipiodol there have been many attempts to use it as a measure of pancreatic function and of fat absorption. Lipiodol is an iodized poppy seed oil, the iodine of which remains bound to the unsaturated double bonds of the fat until after absorption when it is then split off and excreted in the urine as sodium iodide.

The literature concerning the use of Lipiodol as a test of pancreatic function and fat absorption has been briefly reviewed by Silverman and Shirkey (1955) whose modified test still proved to be insufficiently reliable for routine use (Delory, Israels, and Jonasson, 1956; Jones and di Sant 'Agnese, 1963).

In estimating urinary iodide by the nitric acidstarch method, O'Brien, Walker, and Ibbott (1959) demonstrated that the values obtained depended upon accurate control of temperature and on the final concentration of nitric acid in the test. Using this information, Jones and di Sant 'Agnese (1963) devised a simple test for steatorrhoea and claimed complete agreement, in children, between the results of their test and the daily faecal fat output.

This paper describes the results of a trial of this test in children, compared with the daily fat output, interest in the subject being stimulated by the need for a simple, reliable test for steatorrhoea, particularly in paediatric practice.

\section{Methods and Subjects}

Lipiodol absorption test. This was carried out as described by Jones and di Sant 'Agnese (1963). Iodine or pancreatic preparations were stopped for at least 48 hours before the test and inquiry made concerning possible iodine sensitivity.

A urine sample was collected before giving Lipiodol orally $(5 \mathrm{ml}$. up to $10 \mathrm{~kg}$. body weight: $0.5 \mathrm{ml} . / \mathrm{kg}$. between $10-20 \mathrm{~kg}$., and $10 \mathrm{ml}$. over $20 \mathrm{~kg}$. body weight), normal meals were taken, and a second urine sample collected 12-18 hours later when iodine excretion is maximal.

Faecal fat. The daily excretion of faecal fat was

Received May 19, 1966. measured over a minimum four-day period (van de Kamer, ten Bokkel Huinink, and Weyers, 1949) while the child was taking a diet appropriate to the age, ensuring an adequate fat intake. Values in excess of $5 \mathrm{~g}$. faecal fat/day were considered abnormal.

Subjects. The test was carried out on 4 children with coeliac disease before treatment, on 9 children who were on a gluten-free diet and well, and on 11 children with fibrocystic disease of the pancreas, 9 with pancreatic achylia and 2 without achylia. 37 children with a variety of conditions acted as a control group. This group included children under investigation for failure to thrive but whose subsequent progress was satisfactory, children with acute or recurrent respiratory infection, and children with miscellaneous conditions such as anaemia, convulsions, and recurrent enteritis.

The ages ranged from 6 weeks to 14 years, the majority being between 3 and 9 months and 1 and 3 years. The sexes were approximately equal.

\section{Results}

Fig. 1 shows the urinary iodine titres in the five groups of cases. In Fig. 2 the urinary iodine titre is compared with the daily faecal fat output, there being reasonably good agreement between the results of the two tests. When the iodine titre was $1: 8$ or more the faecal fat was less than $5 \mathrm{~g}$./day, the only exceptions being two children with untreated coeliac disease.

Conversely, when the iodine titre was less than $1: 8$ the faecal fat excretion was greater than $5 \mathrm{~g}$./day, with two exceptions. One was a premature twin, examined at 3 months, with a history of failure to thrive but whose subsequent weight progress was satisfactory; the other was a child with fibrocystic disease and meningomyelocele who was severely underweight and too ill to take an adequate diet.

\section{Discussion}

Though there is close agreement in this study between the results of the Lipiodol test and the daily faecal fat excretion, it is not absolute, as reported by Jones and di Sant 'Agnese (1963). 


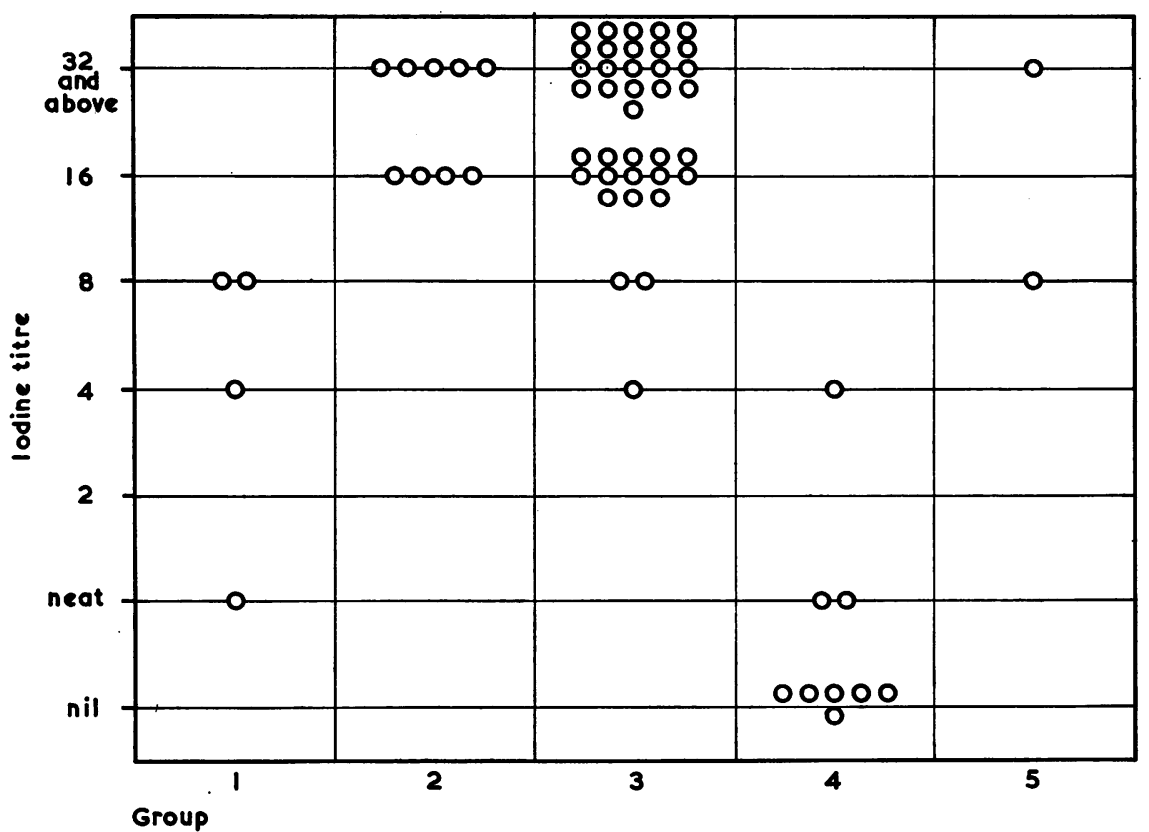

FIG. 1.-Urinary iodine titres in (1) untreated coeliac disease, (2) coeliac disease on treatment, (3) control group, (4) fibrocystic disease with achylia, and (5) without achylia.

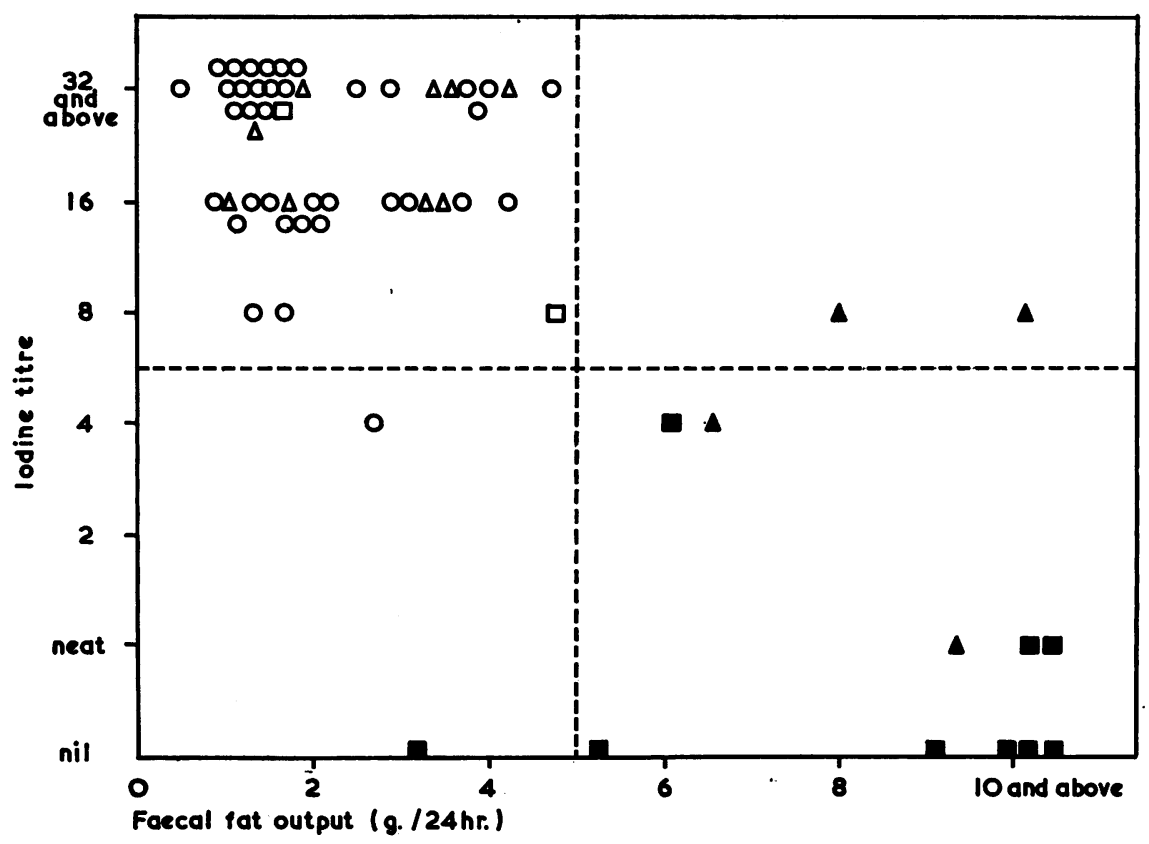

FIG. 2.-Comparison of the urinary iodine titres with daily faecal fat output. O control group; $\Delta$ coeliac disease, untreated; $\Delta$ coeliac disease, on treatment; $\square$ fibrocystic disease, with achylia; $\square$ fibrocystic disease, without achylia. 
Nevertheless, the Lipiodol test, because of its simplicity, can be recommended as a screening test for the presence or absence of steatorrhoea and it can be carried out easily on either out-patients or in-patients.

A urinary iodine titre of $1: 16$ or over is indicative of the absence of steatorrhoea and a level of $1: 2$ or below of the presence of steatorrhoea. Titres of $1: 4$ and $1: 8$ are equivocal and indicate the need to measure faecal fat output.

The Lipiodol test appears to give a more accurate assessment of fat absorption in cases of fibrocystic disease of the pancreas with achylia than in cases with untreated coeliac disease, though the number of the latter (4) is too small for satisfactory assessment.

Since this study was begun Neerhout, Lanzkowsky, Kimmel, Lloyd, Wilson, and Lahey (1964) have devised another test for fat absorption using Lipiodol measuring the iodine levels in the blood, but it lacks the simplicity of the test discussed in this paper.

\section{Summary}

A trial has been made of the Lipiodol test described by Jones and di Sant 'Agnese (1963) for the detection of steatorrhoea and the results compared with the daily faecal fat output.

There is close agreement between the results of the two tests. The Lipiodol test, because of its extreme simplicity, is recommended as a screening test for steatorrhoea.

The authors are grateful to Dr. P. Doherty of Bengué \& Co., Ltd., for the supply of Lipiodol for this trial.

\section{REFERENCES}

Delory, G. E., Israels, S., and Jonasson, H. (1956). The iodized oil (lipiodol) test for fat absorption. Amer. F. Dis. Child., 92, 24.

Jones, W. O., and di Sant 'Agnese, P. A. (1963). Laboratory aids in the diagnosis of malabsorption in pediatrics. I. Lipiodol absorption as a simple test for steatorrhea. $\mathcal{F}$. Pediat., 62, 44.

van de Kamer, J. H., ten Bokkel Huinink, H., and Weyers, H. A. (1949). Rapid method for the determination of fat in feces. f. biol. Chem., 177, 347.

Neerhout, R. C., Lanzkowsky, P., Kimmel, J. R., Lloyd, E. A., Wilson, J. F., and Lahey, M. E. (1964). A new test for fat absorption which employs an iodinated triglyceride. $\mathcal{f}$. Pediat., 65, 701.

O'Brien, D., Walker, D. M., and Ibbott, F. A. (1959). Specificity of the iodized oil test for fat absorption. Pediatrics, 23, 422.

Silverman, F. N., and Shirkey, H. C. (1955). A fat absorption test using iodized oil, with particular application as a screening test in the diagnosis of fibrocystic disease of the pancreas. ibid., 15, 143. 